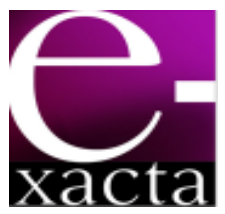

ISSN: 1984-3151

\section{UTILIZAÇÃO DO BAGAÇO DE LARANJA NO TRATAMENTO DE EFLUENTE PROVENIENTE DA LAVAGEM DE JEANS}

\author{
USE OF ORANGE BAGASS IN THE TREATMENT OF \\ EFFLUENT FROM THE WASH JEANS
}

\author{
Ana Paula Ströher ${ }^{1}$; Maraisa Lopes de Menezes ${ }^{2}$; Leila Denise Fiorentin ${ }^{3}$; Nehemias \\ Curvelo Pereira ${ }^{4}$
}

1 Mestre em Engenharia Química. Universidade Estadual de Maringá, 2007. Doutoranda em Engenharia Química PEQ/UEM. Maringá, PR. ana stroher@hotmail.com

2 Mestre em Engenharia Química. Universidade Estadual de Maringá, 2007. Doutoranda em Engenharia Química PEQ/UEM. Maringá, PR. maraisalm@hotmail.com

3 Doutora em Engenharia Química. Universidade Estadual do Oeste do Paraná, 2001. Professora da Universidade Estadual do Oeste do Paraná, PR. leiladeniseff@hotmail.com

4 Doutor em Engenharia Química. Universidade Federal de Sergipe, 1970. Professor da Universidade Estadual de Maringá, PR. nehemias@deq.uem.br 


\section{INTRODUÇÃO}

As indústrias de tintas, têxteis, papel e plástico usam corantes para tingir seus produtos consumindo em seu processo um volume substancial de água. Como resultado, é gerada uma grande quantidade de efluente colorido, resultante da presença de corantes, que mesmo em pequenas quantidades é altamente visível. (CRINI, 2005).

Estima-se que cerca de $15 \%$ da produção mundial de corantes é perdida para o ambiente durante a síntese, processamento ou aplicação destes. Isto é alarmante, considerando-se que essa perda representa um grande lançamento desta classe de compostos no meio ambiente. A principal fonte de perda corresponde à incompleta fixação dos corantes durante a etapa de tingimento das fibras têxteis (GUARATINI e ZANONI, 1999).

A etapa de tingimento é executada para conferir cor aos fios ou tecidos e para aumentar o valor do produto. Os materiais têxteis são tingidos usando uma ampla gama de corantes, técnicas e equipamentos. Os corantes usados pela indústria têxtil são em grande parte sintéticos, tipicamente derivados do alcatrão e do petróleo (EPA, 1997).

Deste modo, métodos para remoção de cor de efluentes industriais têm recebido atenção nos últimos anos. O desenvolvimento de tecnologia adequada para tratamento destes rejeitos tem sido objetivo de grande interesse devido ao aumento da conscientização e rigidez das regulamentações ambientais (HOLME, 1984). As principais técnicas disponíveis na literatura para descoloração das águas de rejeitos envolvem principalmente processos de adsorção, precipitação, degradação química, eletroquímica e fotoquímica, biodegradação e outros (GUARATINI e ZANONI, 1999). Em alguns casos torna-se importante o uso de técnicas mais modernas como os processos de separação por membranas que estão evoluindo como uma solução promissora para muitos problemas associados aos efluentes têxteis. Os processos com membranas podem ser aplicados na remoção de cor e reuso de corantes, redução de carga orgânica, redução e reuso do sal, recuperação do álcool polivinílico (PVA) e outras gomas, recuperação do látex e principalmente para recuperação e reuso da água (SILVA, 2004).

A adsorção é uma das técnicas que tem sido empregada com sucesso para uma remoção efetiva da cor. O primeiro passo para um processo de adsorção eficiente é a escolha de um adsorvente com alta seletividade, capacidade e longa vida. Este deve também estar disponível em grandes quantidades, a um baixo custo (FIGUEIREDO; BOAVENTURA; LOUREIRO, 2000).

Adsorção com carvão ativo é o método mais comum de remoção de cor por adsorção, e, é muito efetivo na remoção de corantes catiônicos mordentes e ácidos e em menor extensão de corantes dispersos, diretos e reativos. Entretanto, devido ao seu alto custo e considerando-se a enorme quantidade de efluente normalmente produzida pela indústria têxtil, pesquisas têm sido recentemente direcionadas para adsorventes alternativos, também chamados de adsorventes de baixo custo ou não convencionais. Estes adsorventes têm sido investigados em escala laboratorial para o tratamento de efluentes coloridos com diferentes graus de eficiência.

O Brasil é atualmente o maior produtor e exportador mundial de laranja e de bagaço de laranja. O bagaço de laranja in natura é um subproduto, que após a extração do suco é abundante. 
Apesar de o suco ser o principal produto da laranja, vários subprodutos, com valor comercial são obtidos durante o seu processo de fabricação. Um dos principais problemas enfrentados pelas indústrias processadoras de suco de laranja é o grande volume de resíduos sólidos e líquidos, produzidos diariamente. Os sólidos, constituídos pelas cascas, sementes e polpas, são na grande maioria dos casos utilizados como componente de ração animal, húmus, farelo de polpa cítrica, cama de frangos, adsorvente, e silagem. Dentre os despejos líquidos, tem-se a "água amarela" e o óleo, a partir do qual pode-se produzir etanol celulósico, óleo essencial, D’limoneno, entre outros produtos. Eles possuem diferentes aplicações no mercado interno e externo, as quais incluem fabricação de produtos químicos e solventes, aromas e fragrâncias, substâncias para aplicação em indústrias de tintas, cosméticos, complemento para ração animal, entre outros (http://georickk.multiply.com/journal/item/6).

Neste trabalho pesquisou-se a capacidade de remoção de compostos poluentes de um efluente têxtil, utilizando-se um resíduo sólido proveniente da indústria de processamento de suco de laranja, denominado de bagaço de laranja. Para tanto, foi realizado um pré-tratamento do efluente têxtil utilizando o processo de ultrafiltração em membrana cerâmica. Seguindo para ao estudo da etapa de adsorção determinou-se $\mathrm{opH}$ ideal do efluente, o tempo de equilíbrio do adsorvente em contato com o efluente, construíram-se as isotermas de adsorção e ajustaram-se aos modelos matemáticos de Freundlich e Langmuir. Ao final do processo avaliou-se a eficiência da combinação dos dois processos de separação em termos de remoção de parâmetros químicos e físicos.

\section{METODOLOGIA}

\subsection{PREPARAÇÃO DO ADSORVENTE}

O bagaço de laranja utilizado foi obtido de uma indústria de processamento de suco de laranja, na região de Maringá. Após sua obtenção o resíduo foi armazenado e mantido à temperatura de $-15^{\circ} \mathrm{C}$. Para a utilização do adsorvente, o bagaço foi descongelado, lavado e seco em secador convectivo à temperatura de $42^{\circ} \mathrm{C}$ e velocidade do ar de $1,3 \mathrm{~m} / \mathrm{s}$ Em seguida, foi caracterizado granulometricamente em tamanhos de partículas de 0,5 mm (FIORENTIN, 2009).

\subsection{EFLUENTE TÊXTIL}

O efluente têxtil utilizado foi fornecido pela CLI, Lavanderia Industrial, situada nas proximidades de Maringá-PR. Este efluente foi oriundo da lavagem exclusiva de jeans que contém o corante reativo azul 5G. Coletou-se um lote de efluente contendo 60 litros. Após a coleta o efluente foi acondicionado em embalagens de 10 litros e armazenado em refrigerador $\mathrm{a}-5^{\circ} \mathrm{C}$.

\subsection{CARACTERIZAÇÃO DO EFLUENTE}

$\mathrm{pH}$ : determinado por meio de um pHmetro Digimed DM 20.

Turbidez: determinada por meio de Espectrofotômetro Hach DR/2010 - Portable Datalogging Spectrophotometer, com comprimento de onda de 860 $\mathrm{nm}$. Os resultados são expressos em FAU (Formazin Attenuation Units, sendo que $1 \mathrm{FAU}$ equivale a 1 NTU). 
Cor: determinada por meio de Espectrofotômetro Hach DR/2010 - Portable Datalogging Spectrophotometer, no comprimento de onda de $455 \mathrm{~nm}$.

Parâmetros Químicos: Sólidos suspensos totais, fixos e voláteis; Sólidos totais, fixos e voláteis; DQO, DBO. Realizados conforme os métodos de química analítica descritos no Standard Methods (CORRÊA JR.; FURLAN, 2003).

\subsection{CARACTERIZAÇÃO DO BAGAÇO DE LARANJA}

As imagens das superfícies das partículas do bagaço da laranja foram realizadas por Microscopia Eletrônica de Varredura (MEV), utilizando o equipamento SHIMADZU SUPERSCAN SS-550. A área superficial específica $\left(S_{B E T}\right)$ foi calculada pelo método $B E T$ (BRUNAUER; EMMETT; TELLER, 1938) e o diâmetro médio de poros (APD) e o volume total de poros (TPV) foram calculados pelo método Barrett-Joyner-Halenda - BJH - (BARRET; JOYNER; HALENDA, 1951). Os dados de adsorção física de $\mathrm{N}_{2}(77 \mathrm{~K})$ foram medidos em um adsortômetro Quantachrome Autosorb-1-C/MS com pressão relativa na faixa de 0,01 a 0,2 . Os valores de $S_{B E T}$, APD e TPV foram obtidos com o auxílio do software Autosorb for Windows ${ }^{\circledR}$ (versão 1.19).

\subsection{ULTRAFILTRAÇÃO}

Ensaios preliminares mostraram que não ocorria o processo de adsorção no efluente bruto. Portanto utilizou-se o processo de ultrafiltração em membrana como pré-tratamento do efluente têxtil. Essa etapa separou componentes do efluente que estavam inibindo o processo de adsorção.

Os ensaios de filtração em membrana foram realizados em uma unidade piloto UF/MF NETZSCH, modelo 027.06-1C1/07-0005/Al construída em aço inoxidável. Nos experimentos utilizou-se uma membrana cerâmica tubular de tamanho de poro 0,01 $\mu \mathrm{m}$, pressão de trabalho 3 bar e temperatura do efluente $30^{\circ} \mathrm{C}$. (MENDES, 2008).

\subsection{ADSORÇÃO EM BATELADA}

Com o permeado obtido da etapa de ultrafiltração foram executados os seguintes testes para otimização do processo de adsorção:

Determinação do $\mathrm{pH}$ ideal: $\mathrm{o} \mathrm{pH}$ do efluente foi ajustado utilizando-se soluções de $\mathrm{NaOH}(0,1 \mathrm{M})$ e $\mathrm{H}_{2} \mathrm{SO}_{4}(0,1 \mathrm{M})$. Variou-se o $\mathrm{pH}$ de 1 a 10 e deixou-se por 24 horas em repouso com $0,025 \mathrm{~g}$ do adsorvente. Após esse período realizou-se a leitura de cor e analisou-se a quantidade de remoção em cada pH.

Determinação do tempo de equilíbrio: inicialmente mediu-se $25 \mathrm{~mL}$ de efluente têxtil e colocou-se em cada um dos 32 erlenmeyers, em duplicata. Em seguida, fez-se o ajuste do $\mathrm{pH}$ do efluente no valor do $\mathrm{pH}$ ideal determinado na etapa anterior. Os erlenmeyers foram levados ao agitador orbital (90 rpm, e $25^{\circ} \mathrm{C}$ ) e adicionou-se $0,025 \mathrm{~g}$ do bagaço de laranja. Em cada intervalo de tempo, pré-determinado, foram retiradas amostras e realizada a leitura da cor em espectrofotômetro Hach DR/2010, durante 120 horas, determinando-se assim o tempo necessário de contato entre $o$ adsorvente e o efluente.

Construção das isotermas: o efluente foi ajustado no valor do $\mathrm{pH}$ ideal e variou-se a massa do adsorvente na faixa de 0,05 até $0,085 \mathrm{~g}$, mantendo-se fixo o volume de solução de $25 \mathrm{~mL}$. A solução foi levada ao agitador orbital $(90 \mathrm{rpm})$ e deixada por 50 horas (tempo de equilíbrio). Atingido esse tempo, realizou-se a leitura da absorbância em um espectrofotômetro Shimadzu Moldelo UV-1601PC no comprimento de onda de $285 \mathrm{~nm}$. A quantidade adsorvida $\left(\mathrm{q}_{\mathrm{eq}}\right)$ foi calculada, em cada amostra, conforme mostra a Equação 1. 


$$
Q_{e q}=\frac{V\left(C_{0}-C_{f}\right)}{m_{s}}
$$

O mesmo procedimento foi realizado para as temperaturas de solução de 25 e $45^{\circ} \mathrm{C}$, determinandose a concentração de equilíbrio $\left(C_{\text {eq }} \mathrm{em} \mathrm{mg} / \mathrm{L}\right.$ ) e a quantidade de material adsorvido $\left(Q_{\mathrm{eq}} \mathrm{em} \mathrm{mg} / \mathrm{g}\right)$.

As isotermas mostram a relação de equilíbrio entre a concentração na fase fluida e a concentração nas partículas adsorventes em uma determinada temperatura (GONÇALVES, 2001). Os modelos de isotermas estudados foram o de Langmuir e o de Freundlich. As variáveis de processo dos modelos de isotermas foram estimados usando-se o pacote computacional de estimação não-linear do software STATISTICA $®$ versão 6.0 , com método de estimativa Quasi-Newton. Após a construção dos gráficos ajustou-se um polinômio de grau 2 para esses dados.

O modelo de Langmuir leva em conta que as forças que atuam na adsorção são similares em natureza àquelas que envolvem combinação química. Langmuir considera que o sistema é ideal, as moléculas são adsorvidas e aderem à superfície do adsorvente em sítios definidos e localizados, com a adsorção em monocamadas em superfície homogênea. Cada sítio pode armazenar uma e somente uma entidade adsorvida e a energia da entidade adsorvida é a mesma em todos os sítios da superfície (ROMEROGONZÁLEZ et al., 2005).

Esta forma de isoterma é a mais utilizada e é expressa pela Equação 2:

$$
Q_{e q}=\frac{k_{L} b C_{e}}{1+k_{L} C_{e}}
$$

O modelo de Freundlich é descrito por uma equação empírica baseada na adsorção sobre uma superfície heterogênea e particularmente empregada para líquidos, conforme apresentado na Equação 3.

$$
Q_{e q}=k_{F} C_{e}^{n}
$$

\section{Resultados e Discussão}

\subsection{CARACTERIZAÇÃo do BAgAÇO DE LARANJA}

A Tabela 1 mostra os valores obtidos para a caracterização do bagaço da laranja seco na temperatura de $42^{\circ} \mathrm{C}$ e fluxo gasoso de $1,3 \mathrm{~m} / \mathrm{s}$.

Tabela 1 - Valores obtidos na análise BET

\begin{tabular}{c|c|c|c}
\hline $\mathbf{T}_{\text {sec }}\left({ }^{\circ} \mathbf{C}\right)$ & $\dot{A}_{\text {sup }}\left(\mathbf{m}^{2} / \mathbf{g}\right)$ & $\mathbf{V}_{\text {poros }}\left(\mathbf{c m}^{3} / \mathbf{g}\right)$ & $\mathbf{D}_{\text {médio }}(\AA)$ \\
\hline $42 \pm 2$ & 3,30 & $2,86 \times 10^{-3}$ & 21,33 \\
\hline
\end{tabular}

Pela Tabela 1, observando os valores obtidos da caracterização do bagaço de laranja em relação à área superficial, volume e diâmetro de poros, evidencia-se que o resíduo tem uma boa capacidade de adsorção, quando comparado com os demais adsorventes. Em trabalhos que se utilizou a casca de soja como adsorvente na remoção dos corantes direto vermelho 80 e 81, ácido azul 92 e ácido vermelho 14, a área superficial foi de $0,7623 \mathrm{~m}^{2} / \mathrm{g}$, enquanto que, para as membranas da casca do ovo utilizadas como adsorvente na remoção dos corantes direto vermelho 80 e ácido azul 25, a área superficial foi de 2,2098 $\mathrm{m}^{2} / \mathrm{g}$ (ARAMI; LIMAEE; MAHMOODI, 2006). Utilizando-se o bagaço de maracujá como adsorvente na remoção do corante reativo azul $5 \mathrm{G}$, a área superficial determinado foi igual a $2,00 \mathrm{~m}^{2} / \mathrm{g}$ (MENEZES, 2010).

A micrografia apresentada na Figura 1 mostra a superfície do bagaço da laranja seco na temperatura de $42^{\circ} \mathrm{C}$. Nota-se que o bagaço possui uma superfície irregular e sem a presença de canais. 


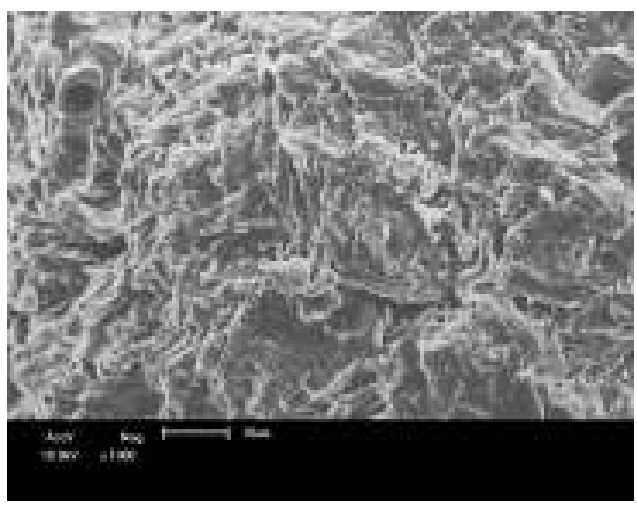

Figura 1 - Microscopia eletrônica de varredura para o bagaço de laranja (ampliação de 1000X)

\subsection{DETERMINAÇÃO DO PH IDEAL}

A casca de laranja é composta de vários grupos funcionais, tais como amino e carboxil, os quais podem também ser afetados pelo $\mathrm{pH}$ da solução. Assim, procurou-se analisar a influência que o $\mathrm{pH}$ da solução possui em relação à porcentagem de remoção de cor do efluente, conforme mostra a Figura 2.

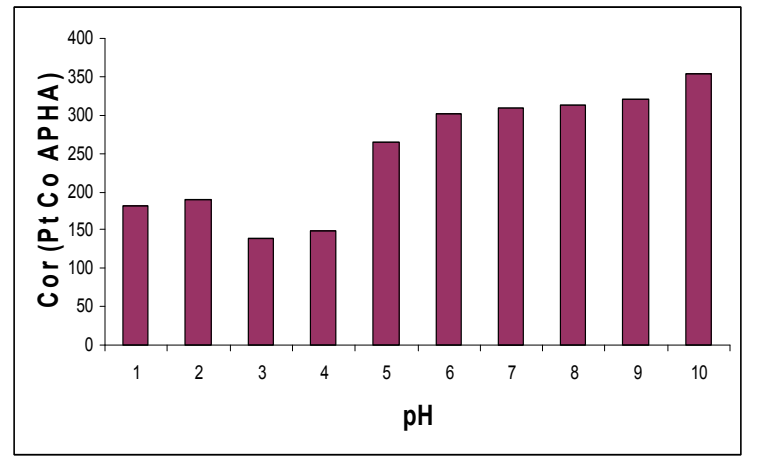

Figura 2 - Efeito do pH na remoção de cor do efluente pelo bagaço de laranja.

A Figura 2 mostra que no $\mathrm{pH}$ ajustado no valor igual a 3 , proporcionou a maior remoção de cor do efluente. À medida que se aumenta o pH se tem uma diminuição da remoção de cor.

\subsection{Determinação do TeMPo de EquiLíbrio}

A Figura 3 mostra a variação de cor no efluente durante 120 horas de experimentos em batelada.

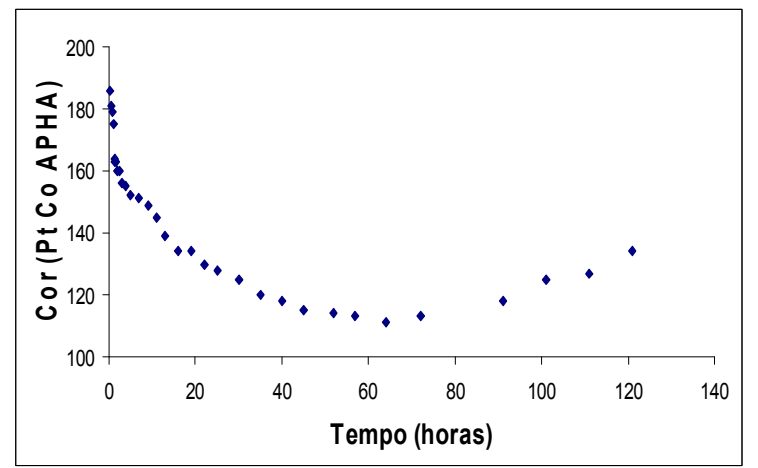

Figura 3 - Variação de cor no efluente em relação ao tempo de contato adsorvente/efluente.

O tempo de equilíbrio corresponde ao tempo de contato necessário para que o equilíbrio entre as fases seja atingido.

Da Figura 3, observa-se que a cinética de adsorção é lenta, uma vez que só com aproximadamente 50 horas de operação é que se tem o equilíbrio. Nota-se também que a partir de 60 horas tem-se um aumento de cor no sistema, ocorrendo provavelmente o processo de dessorção (os componentes do efluente adsorvidos pelo bagaço retornam para o efluente). Desta forma, verificou-se que o adsorvente alternativo em questão, apresenta lenta adsorção, porém grande capacidade de retenção de compostos do efluente têxtil.

\subsection{ISOTERMAS DE ADSORÇÃO}

As isotermas representam a relação de equilíbrio entre a concentração na fase fluida e a concentração nas partículas adsorventes em uma determinada temperatura. 
A Figura 4 mostra as isotermas de adsorção para o bagaço de laranja nas temperaturas de 25 e $45^{\circ} \mathrm{C}$.

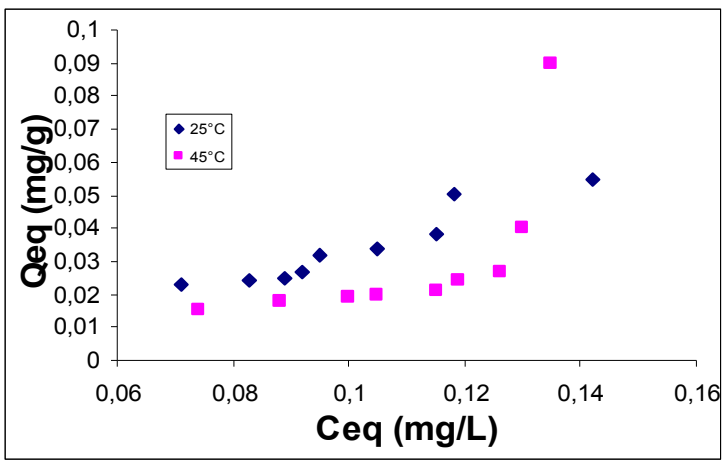

Figura 4 - Isotermas de adsorção para o bagaço de laranja nas temperaturas de 25 e $45^{\circ} \mathrm{C}$.

Nota-se na Figura 4 que 0 aumento de $20^{\circ} \mathrm{C}$ na temperatura, diminui consideravelmente a quantidade adsorvida pelo bagaço de laranja. Assim, para uma concentração de equilíbrio correspondente a 0,012 $\mathrm{mg} / \mathrm{L}$, tem-se uma remoção de $0,04 \mathrm{mg} / \mathrm{g}$ do efluente na temperatura de $25^{\circ} \mathrm{C}$ e para um aumento de $45^{\circ} \mathrm{C}$ mantida a concentração de equilíbrio, ocorreu uma remoção de $0,025 \mathrm{mg} / \mathrm{g}$.

\subsection{AJUStes dos MOdELOS DE LANGMUIR E}

\section{FREUNDLICH}

Aos dados experimentais, ajustaram-se os parâmetros dos modelos de isotermas de Langmuir e Freundlich. As Figuras 5, 6, 7 e 8 mostram os ajustes dos coeficientes dos modelos de Langmuir e Freundlich aos dados experimentais, na determinação da isoterma de adsorção do efluente usando o bagaço de laranja, para as temperaturas de solução de 25 e $45^{\circ} \mathrm{C}$.

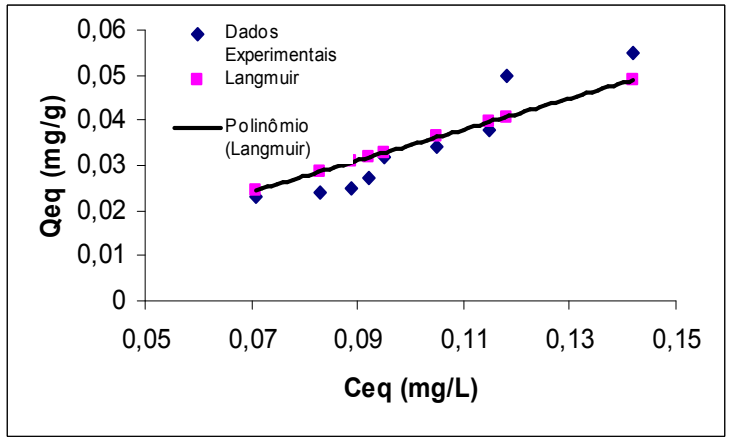

Figura 5 - Ajuste ao modelo de Langmuir para isoterma de $25^{\circ} \mathrm{C}$.

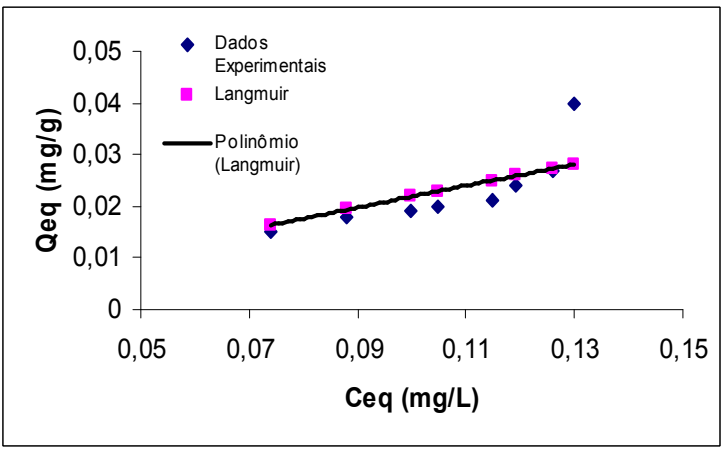

Figura 6 - Ajuste ao modelo de Langmuir para isoterma de $45^{\circ} \mathrm{C}$.

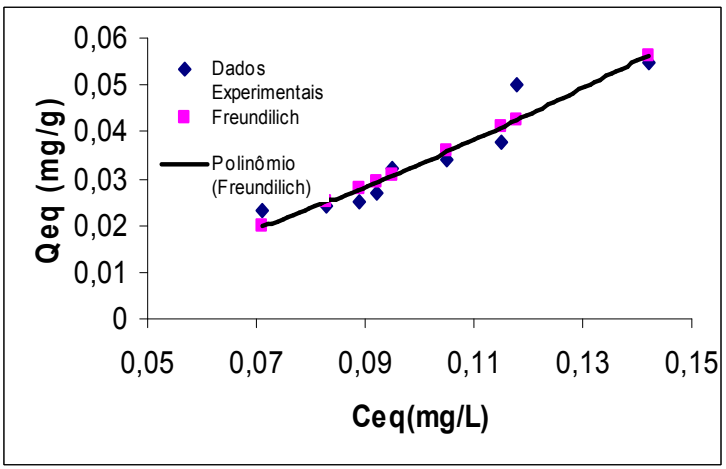

Figura 7 - Ajuste ao modelo de Freundlich para isoterma de $25^{\circ} \mathrm{C}$. 


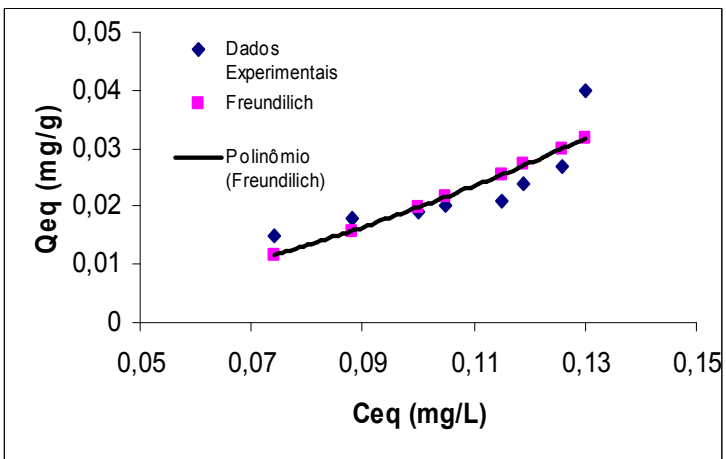

Figura 8 - Ajuste ao modelo de Freundlich para isoterma de $45^{\circ} \mathrm{C}$.

Observa-se pelas Figuras 5 a 7 que ambos os modelos estudados não se ajustaram bem aos dados experimentais, entretanto, com base no coeficiente de correlação, o modelo de Freundlich foi o que melhor representou os dados experimentais.

As Tabelas 2, 3, 4 e 5 apresentam os valores do coeficiente de correlação, da quantidade de compostos poluentes adsorvidos pelo bagaço $\left(Q_{0}\right)$ e da constante de equilíbrio $\left(k_{L}\right)$ para a Equação de Langmuir, bem como os valores da capacidade de adsorção $\left(k_{F}\right)$ e da constante $n$, para a Equação de Freundlich.

Tabela 2 - Valores dos coeficientes de Langmuir para isoterma de $25^{\circ} \mathrm{C}$.'

\begin{tabular}{c|c}
\hline $\mathbf{R}^{\mathbf{2}}$ & 0,8037 \\
\hline $\mathbf{Q}_{\mathrm{eq}}(\mathbf{m g} / \mathbf{g})$ & 740,1018 \\
\hline $\mathbf{k}_{\mathrm{L}}(\mathbf{1} / \mathbf{m g})$ & 0,000466 \\
\hline
\end{tabular}

Tabela 3 - Valores dos coeficientes de Langmuir para isoterma de $45^{\circ} \mathrm{C}$.

\begin{tabular}{c|c}
\hline $\mathbf{R}^{\mathbf{2}}$ & 0,5708 \\
\hline $\mathbf{Q}_{\mathrm{eq}}(\mathbf{m g} \mathbf{g})$ & 0,5145 \\
\hline $\mathbf{k}_{\mathbf{L}}(\mathbf{1} / \mathbf{m g})$ & 0,4440 \\
\hline
\end{tabular}

Tabela 4 - Valores dos coeficientes de Freundlich para

\begin{tabular}{c|c}
\multicolumn{2}{|c}{ isoterma de $25^{\circ} \mathrm{C}$} \\
\hline $\mathbf{R}^{\mathbf{2}}$ & 0,9114 \\
\hline $\mathbf{k}_{\mathbf{F}}$ & 1,0866 \\
\hline $\mathbf{n}$ & 0,6596 \\
\hline
\end{tabular}

Tabela 5 - Valores dos coeficientes de Freundlich para isoterma de $45^{\circ} \mathrm{C}$.

\begin{tabular}{c|c}
\hline $\mathbf{R}^{\mathbf{2}}$ & 0,7003 \\
\hline $\mathbf{k}_{\mathbf{F}}$ & 1,2146 \\
\hline $\mathbf{n}$ & 0,5595 \\
\hline
\end{tabular}

\subsection{CARACTERIZAÇÃo do EFLUENTE PARA CADA ETAPA DE TRATAMENTO}

As Tabelas 6, 7, 8 e 9 apresentam os resultados obtidos nas análises físico químicas realizadas durante cada etapa do processo.

De acordo com a Tabela 6 , não houve redução significativa do valor de $\mathrm{pH}$ com a etapa de ultrafiltração e nem com a etapa de adsorção, uma vez que o efluente foi previamente ajustado em $\mathrm{pH} 3$ nesta última etapa. Já para o parâmetro cor houve redução de $70,94 \%$ para a etapa de ultrafiltração e $46,15 \%$ para a adsorção em bagaço de laranja. Para o parâmetro turbidez, a redução foi de 94,94 e 54,54\%, respectivamente para $o$ efluente permeado $\mathrm{e}$ adsorvido.

Tabela 6 - Análises físicas em cada etapa do processo de tratamento

\begin{tabular}{c|c|c|c}
\hline Efluente & $\mathbf{p H}$ & $\begin{array}{c}\text { Cor } \\
\text { (PtCo APHA) }\end{array}$ & $\begin{array}{c}\text { Turbidez } \\
\text { (FAU) }\end{array}$ \\
\hline Bruto & 10,43 & 1700 & 435 \\
\hline Permeado & 10,23 & 494 & 22 \\
\hline Adsorvido & 3,00 & 266 & 10 \\
\hline
\end{tabular}

Tabela 7 - Análises químicas em cada etapa do processo de tratamento.

\begin{tabular}{c|c|c}
\hline Efluente & DBO (mg/L) & DQO (mg/L) \\
\hline Bruto & 387 & 1210 \\
\hline Permeado & 51 & 210 \\
\hline Adsorvido & 126 & 350 \\
\hline
\end{tabular}

Para os parâmetros DBO e DQO, a Tabela 7 mostra que se obteve uma redução de $86,82 \%$ e $82,64 \%$, 
respectivamente, na etapa de ultrafiltração. Já na etapa de adsorção em bagaço de laranja, houve um aumento de $147,05 \%$ no parâmetro DBO e $66,66 \%$ para a DQO. Esse aumento se deve ao fato de o adsorvente em questão ser constituído basicamente de matéria orgânica e em contato com o efluente em um intervalo de tempo consideravelmente alto, ele passa a se degradar, liberando essa matéria orgânica para o meio.

Tabela 8 - Análises químicas em cada etapa do processo de tratamento.

\begin{tabular}{c|c|c|c}
\hline Efluente & $\mathbf{S S T}(\mathbf{m g} / \mathbf{L})$ & $\mathbf{S S F}(\mathbf{m g} / \mathbf{L})$ & $\mathbf{S S V}(\mathbf{m g} / \mathbf{L})$ \\
\hline Bruto & 318 & 246 & 72 \\
\hline Permeado & 93 & 75 & 18 \\
\hline Adsorvido & 128 & 92 & 36 \\
\hline
\end{tabular}

A Tabela 8 mostra a variação da quantidade de sólidos suspensos totais, fixos e voláteis, em cada etapa do processo. Analisando-se a quantidade de sólidos suspensos totais, uma vez que essa quantidade corresponde à soma dos sólidos suspensos fixos e voláteis, observou-se uma diminuição correspondente a $70,75 \%$ na etapa de ultrafiltração e um aumento de $37,64 \%$ com a etapa de adsorção, novamente, devido à degradação do bagaço de laranja.

A Tabela 9 apresenta as quantidades de sólidos totais, fixos e voláteis presentes no efluente em cada etapa do tratamento em estudo.

Tabela 9 - Análises químicas em cada etapa do processo de tratamento.

\begin{tabular}{c|c|c|c}
\hline Efluente & $\mathbf{S T}(\mathbf{m g} / \mathbf{L})$ & $\mathbf{S F}(\mathbf{m g} / \mathbf{L})$ & $\mathbf{S V}(\mathbf{m g} / \mathbf{L})$ \\
\hline Bruto & 3835 & 2144 & 1691 \\
\hline Permeado & 1135 & 967 & 168 \\
\hline Adsorvido & 1520 & 993 & 527 \\
\hline
\end{tabular}

Para a quantidade de sólidos totais, conclui-se da Tabela 9, que com a etapa de ultrafiltração foi possível uma redução de $70,40 \%$ e um aumento de $33,9 \%$ na etapa de adsorção.

\section{CONCLUSÕES}

Os resultados deste trabalho mostraram que o bagaço de laranja apresenta uma grande capacidade de adsorção de compostos poluentes de um efluente têxtil. Porém é necessário um pré-tratamento do efluente, pois, testes iniciais mostraram que não ocorreu o processo de adsorção com o efluente bruto. Os resultados obtidos com a caracterização da superfície desse resíduo (em relação à área superficial, volume e diâmetro de poros), evidenciouse que o resíduo tem uma boa capacidade de adsorção, quando comparado com os demais adsorventes alternativos apresentados na literatura. Além disso, notou-se que o bagaço de laranja possui uma superfície irregular e sem a presença de canais. $\mathrm{Na}$ etapa de adsorção o efluente com pH ajustado em 3 , foi o que se obteve maior remoção de cor pelo bagaço de laranja. $O$ tempo de contato adsorvente/efluente determinado foi de 50 horas, ou seja, após esse período o adsorvente encontra-se saturado. $\mathrm{O}$ ajuste dos modelos matemáticos às isotermas mostrou que o modelo de Freundlich apresentou os maiores coeficientes de correlação garantindo a melhor representatividade dos dados.

Quanto à eficiência dos processos, a etapa de separação por membranas apresentou boas remoções de todos os parâmetros avaliados. Já para a etapa de adsorção em bagaço de laranja, notou-se aumento da matéria orgânica (em termos dos parâmetros DQO e DBO) e da quantidade de sólidos no efluente. A causa deste aumento foi 0 tempo de equilíbrio consideravelmente alto (50 horas), que causou a degradação do bagaço de laranja em contato com o efluente. Por outro lado o tratamento por adsorção em bagaço de laranja proporcionou uma significativa redução de cor e turbidez do efluente $(46,15$ e $54,54 \%$, respectivamente).

Embora tenha ocorrido um aumento de DQO, DBO e sólidos na etapa de adsorção, a combinação dos dois 
processos de separação reduziu significativamente os parâmetros estudados e o bagaço de laranja mostrouse uma boa opção alternativa para remoção de cor e turbidez de um efluente têxtil.

\section{NOMENCLATURA}

$\mathrm{C}_{0}$ - é a concentração inicial da solução em $\mathrm{t}=0$, em $\mathrm{mg} / \mathrm{L}$.

$\mathrm{C}_{\text {eq }}$ - é a concentração de equilíbrio ( $\left.\mathrm{mg} / \mathrm{L}\right)$.

$\mathrm{C}_{f}$ - é a concentração de efluente final, em $\mathrm{mg} / \mathrm{L}$.

$V$ - é o volume de efluente nos frascos em $L$.

$\mathrm{m}_{s}$ - é a massa do adsorvente (massa seca) em g.

$Q_{e q}$ - é a quantidade adsorvida por massa de adsorvente (mg/g ou meq/g).
$C_{e}-$ é concentração no fluido ( $\mathrm{mg} / \mathrm{L}$ ou $\left.\mathrm{meq} / \mathrm{L}\right)$,

$k_{L}$ - é a constante de equilíbrio ( $\mathrm{mg}$ ou meq adsorvato/g adsorvente), relacionada à energia livre de adsorção, que corresponde à afinidade entre a superfície do adsorvente e o soluto.

$B$ - é a constante que representa a cobertura de adsorvato em uma monocamada ( $\mathrm{L} / \mathrm{mg}$ ou $\mathrm{L} / \mathrm{meq}$ ), ou seja, a máxima adsorção possível.

$\mathrm{k}_{F}$ - é a capacidade de adsorção de Freundlich (mg/L). $n$ - constante que incorpora todos os fatores que afetam o processo de adsorção, tais como capacidade de adsorção e intensidade.

\section{REFERÊNCIAS}

ARAMI, M.; LIMAEE, N. Y.; MAHMOODI, N. M. Investigation on the Adsorption Capability of Egg Shell Membrane Towards Model Textile Dyes. Chemosphere, v. 65, p.1999-2008, 2006.

BRUNAUER, S., EMMETT, P. H., TELLER, E. Adsorption of gases in multimolecular layers. Journal of the American Chemical Society, v. 6, p. 309-319, 1938.

BARRET, E. P.; JOYNER, L. G.; HALENDA P. P. The determination opf pore volume and area distributions in porous substances Journal of American Chemistry Society, v. 73, n. 1, p. 373, 1951.

CORRÊA JR. B.; FURLAN, L. T. Redução do consumo de água e da vazão de efluentes através do gerenciamento das fontes e reutilização de águas - a experiência de Paulínia. Petro \& Química, $\mathrm{n}^{\circ} 251$, p.72-78, 2003.

CRINI, G. Non-conventional low-cost adsorbents for dye removal: a review. Bioresource Technology, v. 97, n. 9, p.1061-1085, 2005.
EPA - Environmental Protection Agency. Profile of the Textile Industry. Washington, September, 1997.

FIGUEIREDO, S. A.; BOAVENTURA, R. A.; LOUREIRO, J. M. Color removal with natural adsorbents: modeling, simulation and experimentation. Separation and Purification Technology, v. 20, p. 129141, 2000.

FIORENTIN, L. D. Remoção de Corante de Efluentes da Industria Têxtil Utilizando Processos com Membranas e Adsorção em Bagaço de Laranja. Tese de Doutorado em Engenharia Quimica - Universidade Estadual de Maringá, Maringá, 163p. 2009.

GONÇALVES, G. C. Clarificação do caldo de cana de açúcar utilizando processos com membranas e adsorção com carvão ativado proveniente do bagaço de cana. Tese de Doutorado em Engenharia Quimica - Universidade Estadual de Maringá, Maringá, 142p. 2001.

GUARATINI, C. C. I.; ZANONI, M. V. B. Corantes Têxteis. Revista Química Nova, v. 23, p.71-78, 1999.

HOLME, J. Developments in the Chemistry and Technology of Organic Dyes. J. Griffiths Ed., Blackwell Scent. Publ., Oxford, 1984. 
JORNAL DOS RESÍDUOS, Multiply. Disponível em: <http://georickk.multiply.com/journal/item/6>. Acesso em: set. 2007.

MENDES, M. Recuperação da água de uma lavanderia industrial utilizando processo combinado com membrana e posterior adsorção. Dissertação de Mestrado em Engenharia Química - Universidade Estadual de Maringá, Maringá, 80p. 2008.

MENEZES, M. L. Remoção do corante reativo azul $5 G$ a partir de soluções aquosas utilizando o bagaço do maracujá amarelo como adsorvente. Dissertação de Mestrado em Engenharia Química - Universidade Estadual de Maringá, Maringá, 115p. 2010.
ROMERO-GONZÁLEZ, J.; PERALTA-VIDEA, J. R.; RODRIGUEZ, E.; RAMIREZ, S. L.; GARDEATORRESDEY, J. L.. Determination of thermodynamic parameters of $\mathrm{Cr}$ (VI) adsorption from aqueous solution onto Agave lechuguilla biomass. Journal of Chemical Thermodynamics, V.37, p.347-351, 2005.

SILVA, A. F. Preparação, caracterização e aplicaçãode membranas de poli(fluoreto de vinilideno) para a redução de cor de efluente têxtil modelo. Dissertação de Mestrado em Engenharia Quimica Universidade Estadual de Maringá, Maringá, 145p. 2004. 